\title{
Duration discrimination in a series of rhythmic events
}

\author{
ANDREA R. HALPERN \\ Stanford University, Stanford, California 94305 \\ and \\ CHRISTOPHER J. DARWIN \\ University of Sussex, Brighton, Sussex BN1 9QG, England
}

\begin{abstract}
Duration discrimination of the last of a series of four clicks was investigated. Examination of psychophysical functions from eight subjects revealed evidence for a Weber's law model relating discrimination to base interclick interval. Also, the point of subjective equality was seen to change reliably as a function of base rate.
\end{abstract}

One of the easier components of Western music to describe and conceptualize is its system of rhythm. The division of a unit beat into two or three equal parts and the same divisions of the subunits create most of the building blocks of our rhythmic system. Despite its mathematical simplicity, the actual execution of rhythmic patterns is fraught with all of the limitations of the human sensorimotor system. And, of course, music as an aesthetic experience demands a certain latitude in approximating rhythmic patterns. These inaccuracies have in fact been shown to exist in music performance by Gabrielsson (1974), Povel (1977), and Rasch (1979).

Numerous researchers have studied the ability of subjects to produce accurate rhythmic sequences in the laboratory. On the whole, subjects are quite good at tasks such as synchronizing taps with an external stimulus or continuing the sequence without any external aid. However, small but consistent errors in reproduction can be found and to some extent accounted for by quantitative models (Best \& Bartlett, 1972; Fraisse, 1963; Michon, 1967; Povel, 1981). For instance, Povel (1981) found that reproduction of simple sequences was most accurate when the durations in the sequences formed simple ratios. Conversely, complex ratios tended toward simplicity during reproduction.

Given these characteristics of rhythmic performance, one may ask to what extent the listener can detect deviations in such a stimulus. Duration dis-

\footnotetext{
This research was undertaken while the first author was a visitor at the Laboratory of Experimental Psychology at the University of Sussex. Financial support was provided by an NSF graduate fellowship to the first author and a grant from the Science Research Council to N. S. Sutherland. Address correspondence to Andrea R. Halpern, Psychology Department, Building 420, Stanford University, Stanford, California 94305.
}

crimination has long been of interest to psychologists (see Allan, 1979, for a review). As Allan points out, one of the central problems in this area of research is specifying the psychophysical law, if any, relating objective and subjective duration. In particular, there has been continuing debate over the applicability of Weber's law as the psychophysical law of duration discrimination. Getty $(1975,1976)$ has found evidence to support a generalized form of Weber's law, while Allan and her colleagues have found evidence for alternative models.

Most duration discrimination studies have used a variation of a two-duration paradigm. Subjects are presented two filled or empty intervals and are asked to choose the longer (or shorter) of the two (e.g., Abel, 1972; Getty, 1975). Our interest was the discrimination performance of subjects detecting deviations in a series of rhythmic events. At a concert, a listener is exposed to a quasi-regular pattern of pulses from the music (the beat) against which the inaccuracies mentioned above are heard and evaluated. At what point does a deviation become perceptible?

In partial answer to this question, Lunny (1974) devised a metronome whose every fourth click could be adjusted. A regular beat was established, and Lunny's task (he was the sole subject) was to manipulate the fourth click until the irregularity was just noticeable (it was not stated whether the irregular beat was early or late with respect to the correct beat). The result, after many weeks of practice, was a regularlooking function relating interclick interval to the least discernible irregularity. The shape of the plot was approximately exponential over a wide range of interclick intervals (30-3,200 msec) but approximately linear for the interval range most often used for musical tempi (500-1,500 msec).

Our study attempted to measure more precisely the relationship between tempo and discriminability, 
using techniques common in the duration discrimination literature. Trials of four clicks were presented; the fourth click varied from being $10 \%$ (of the interclick interval) early to $10 \%$ late. Listeners were relatively unpracticed and had a variety of musical backgrounds. Psychometric functions were obtained, and an analysis of the fitted normal ogives provided the dependent measure. In particular, the question of whether Weber's law can adequately characterize the data was examined.

\section{METHOD}

\section{Subjects}

Participants were eight members of the University of Sussex community. A wide range of musical education was represented by the subjects, from 0 to 12 years of formal music study (median $=1$ year). Subjects were paid for $3 \mathrm{~h}$ of participation.

\section{Stimuli}

Stimulus generation and data collection were controlled by a PDP-12 computer. All stimuli were .125-msec clicks, low-pass filtered at $3 \mathrm{kHz}$ (Kemo VBF/8), and were presented at a comfortable listening level through TDH-39 headphones via a Revox amplifier. Testing took place individually in a soundproof chamber.

A trial consisted of a series of four clicks. The first three clicks were equally spaced in time, having an interclick interval (base ICI) of $400,550,700,850,1,000,1,150,1,300$, or $1,450 \mathrm{msec}$. These base ICIs were chosen to span the range of tempi typically found in music (equivalent to a range of 150 to 41 beats per minute). The fourth click in the trial came at the end of an ICI that differed from the base ICI. This deviation amounted to $0 \%, 2 \%, 4 \%$, $6 \%, 8 \%$, or $10 \%$ of the base ICI. Since each deviation could be either longer or shorter than the base ICI by $x \%$, there were a total of 11 possible values of the deviation for each base ICI (see Table 1). The values of the deviations were calculated after pilot experiments showed that a $10 \%$ deviation would be clearly detectable at the longest and shortest base ICIs.

A given experimental block used a single base duration. A block consisted of 17 observations of each of the 11 deviations for a total of 187 trials. In each group of 11 trials within the block, each deviation appeared once in a random order. Different random orders were matched with different blocks for each subject.

\section{Procedure}

The subject initiated a block by pressing a foot pedal. After a gap of $1,500 \mathrm{msec}$, the click sequence was heard. Subjects were instructed to press the left button on a response board if the last click sounded "early" and the right button if it sounded "late." Responses of "don't know" were not permitted. Alternatively, they could elect to rehear the trial by pressing the foot pedal. The

Table 1

Base ICI, Step Size, and Deviations of the Fourth Click in a Trial (in Milliseconds)

\begin{tabular}{|c|c|c|c|c|c|c|}
\hline \multirow{2}{*}{$\begin{array}{c}\text { Base } \\
\text { ICI }\end{array}$} & \multirow{2}{*}{$\begin{array}{l}\text { Step } \\
\text { Size }\end{array}$} & \multicolumn{5}{|c|}{ Deviation } \\
\hline & & $2 \%$ & $4 \%$ & $6 \%$ & $8 \%$ & $10 \%$ \\
\hline 400 & 8 & 8 & 16 & 24 & 32 & 40 \\
\hline 550 & 11 & 11 & 22 & 33 & 44 & 55 \\
\hline 700 & 14 & 14 & 28 & 42 & 56 & 70 \\
\hline 850 & 17 & 17 & 34 & 51 & 68 & 85 \\
\hline 1000 & 20 & 20 & 40 & 60 & 80 & 100 \\
\hline 1150 & 23 & 23 & 46 & 69 & 92 & 115 \\
\hline 1300 & 26 & 26 & 52 & 78 & 104 & 130 \\
\hline 1450 & 29 & 29 & 58 & 87 & 116 & 145 \\
\hline
\end{tabular}

next trial was initiated by pressing a response button. A visual display informed the subjects of the number of trials remaining in the block. No other feedback was given.

The experiment was conducted in four sessions: the first lasted about $1 \mathrm{~h}$ and the other three about $45 \mathrm{~min}$. The first session began with two blocks of 88 practice trials at two base ICIs not used in the experiment $(600$ and $1,200 \mathrm{msec})$. Then two blocks of 187 trials each were presented. The subsequent three sessions involved presentation of two blocks, for a total of eight blocks. Short rest periods separated the blocks within a session. During one rest period, subjects filled in a questionnaire about their musical backgrounds. Unknown to the subjects, the first 11 trials in each block were considered warm-ups and were not included in the data analysis. This left a total of 16 observations on each of 11 deviations for each base ICI for each subject.

The order of blocks over sessions, and whether the faster or slower block was presented first within a session, were counterbalanced over subjects.

\section{RESULTS}

Psychometric functions were derived for each subject by plotting the number of trials (of 16) in which the fourth click was judged "late" as a function of the deviation. The data were submitted to a probit analysis, which fits a normal ogive to each function. The two measures of interest resulting from this analysis are the standard deviation (SD) of the fitted normal distribution (a measure of discriminability) and the mean of the fitted distribution (the point of subjective equality, or PSE-a measure of response bias). The normal distribution appears to provide an adequate fit to the data. Of 64 probit analyses (8 subjects $\times 8$ base ICIs), only 7 resulted in a chi-square value significant at the .01 level. No systematic differences among subjects due to musical background, or any other demographic factors, were found.

\section{Standard Deviation}

Because the corresponding deviations at each base ICI were proportionally equal, a mechanism obeying Weber's law would produce a linear increase of SD when plotted against base ICI. The obtained data are shown in Figure 1. Each data point represents the mean of eight subjects. The best-fitting straight line for these points was computed by the least squares method. The linear fit is quite good, with an equation of $y=.39 x+28.25$ resulting in a correlation of .96 . An analysis of variance on these data and a subsequent test for trend revealed a highly significant linear component $[F(1,55)=48.87, p<.001]$ and no other principal contributions to the between-treatments sum of squares.

The Weber's fraction is defined as the standard deviation/base ICI, or SD/B. The Weber fraction for each of the base ICIs (averaged over eight subjects) is shown in Table 2. An analysis of variance revealed no differences between the fractions for the base ICIs. It is interesting to note the larger values of SD/B for the two shortest base ICIs. The Weber fraction has often been shown to increase for short intervals (e.g., 


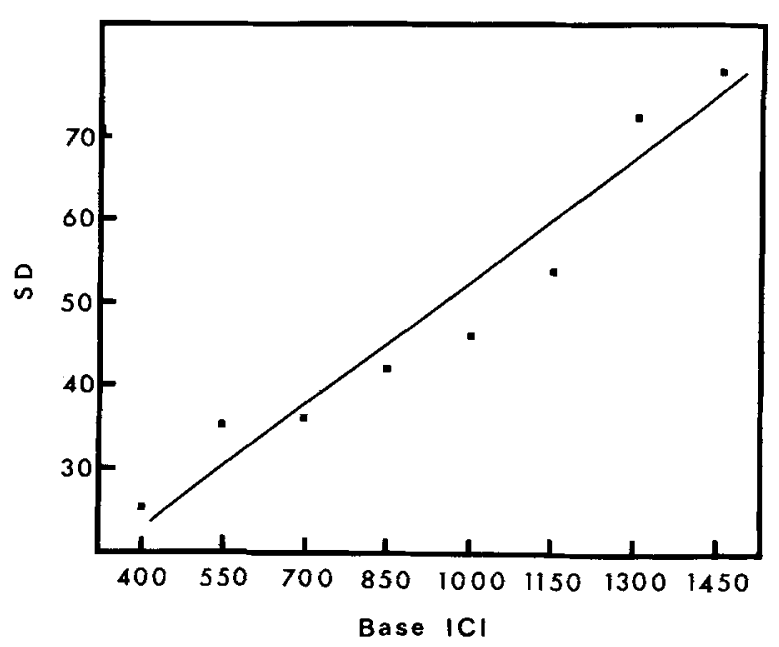

Figure 1. Base ICI plotted against mean standard deviation of each paychometric function (in milliseconds).

Getty, 1975; Stott, 1933); however, the effect has proved significant only at intervals shorter than the $400 \mathrm{msec}$ used here. The average value of SD/B in this study was .054, which agrees well with the value of "about .05 " reported by Getty (1975) for his two-interval duration discrimination task.

\section{Point of Subjective Equality}

This measure is an indication of the constant error of a subject's judgment. Since there were 11 deviations for each base ICI, a PSE of $6(0 \%$ deviation) means that there was no error; the subject's estimate of the deviation that sounded neither early nor late was objectively correct. A PSE of greater than 6 implies that the subject's notion of a $0 \%$ deviation was actually a late deviation; it is a bias to respond "early." Table 2 reports the mean PSE for each base ICI, both in deviation units (" 1 " to " 11 ") and their millisecond equivalents. As the millisecond value of the deviation units increased proportionally to the base ICI, the PSE should have remained constant if

Table 2

Mean Weber Fraction (SD/B), Point of Subjective Equality (PSE), and Difference Limen (DL) for Each Base ICI

\begin{tabular}{ccccc}
\hline Base & & \multicolumn{2}{c}{ PSE } \\
ICI & SD/B & $\begin{array}{c}\text { Deviation } \\
\text { Units }\end{array}$ & $\begin{array}{c}\text { Milli- } \\
\text { seconds* }\end{array}$ & DL \\
\hline 400 & .064 & 6.23 & +1.84 & 17.50 \\
550 & .065 & 6.12 & +1.32 & 24.21 \\
700 & .052 & 5.79 & -2.94 & 24.72 \\
850 & .050 & 5.64 & -6.12 & 28.91 \\
1000 & .046 & 5.56 & -8.80 & 31.00 \\
1150 & .047 & 5.52 & -11.04 & 36.81 \\
1300 & .056 & 5.36 & -16.64 & 49.55 \\
1450 & .055 & 5.27 & -21.17 & 54.16 \\
\hline
\end{tabular}

*Millisecond equivalents $=($ deviation units -6$) \times$ step size. there were no systematic dependence of PSE on base ICI. However, the table clearly reflects a pattern of decreasing PSE as base ICI becomes slower. With fast rates, performance is quite accurate. As the rate slows, subjects are more and more inclined to call deviations "late." These differences in PSE are reliable, as shown by an analysis of variance $[F(7,49)=2.76$, $\mathrm{p}<.05]$.

\section{DISCUSSION}

Although no model has been formally evaluated for the data presented here, support has been found for a Weber's law model of simple rhythmic discrimination. The Weber fraction $\mathrm{SD} / \mathrm{B}$ remained fairly constant over the base ICIs tested. It does not continually decrease toward 0 , as would be predicted for varieties of models based on Creelman's (1962) countermodel (Getty, 1975). There are several methodological differences between the present study and typical duration discrimination experiments (e.g., Abel, 1972). The base durations investigated here were within a narrower range than is common; in particular, the shortest base ICI $(400 \mathrm{msec})$ is longer than the durations of under $100 \mathrm{msec}$ that are often studied. The presentation of two rather than one standard interval on each trial and the required judgment of "early" or "late" presumably made the stimulus more rhythmically meaningful than is usual in this type of experiment.

The decrease in the PSE with slower base ICI corresponds to a similar effect shown in production of rhythmic sequences. Best and Bartlett (1972) found that, in a synchronization task, errors of anticipation increased as the intervals between stimuli became longer. If subjects also perceptually anticipate the beat for slow rates, then the actual beat will be heard as "late." This is precisely the effect found here: subjects called more responses "late" for slower tempi. Even so, the most "incorrect" PSE was $-21.17 \mathrm{msec}$ at a base ICI of $1,450 \mathrm{msec}$, an error of only $1.46 \%$. The small biases shown in this experiment may be due to the presentation of two accurate interclick intervals on each trial before the subject made a judgment.

The absolute level of discrimination in the experiment may be considered next. Although the analyses were performed on the standard deviations of the psychometric function, discriminability may be more concretely illustrated by considering the corresponding difference limens (DL). The DL is one-half the interquartile range of the psychometric function, or the stimulus difference correctly detected $50 \%$ of the time. In a normal distribution, the $\mathrm{DL}$ is .68 of the standard deviation. These values may be seen in the last column of Table 2 and may be interpreted as the limits within which a musician should operate when establishing a basic beat in a musical performance. 
Larger deviations will be reliably perceived by listeners and understood as expressive devices, errors, or a different kind of rhythmic unit, depending on the context.

These limits are also applicable to devising theories of rhythm perception and especially for computer simulation of the theories. For instance, LonguetHiggins (1976) was obliged to include a "tolerance" factor for the rhythm component of his program, which transcribes a live musical performance. He chose a value of $100 \mathrm{msec}$; a duration d was transcribed as the rhythmic unit $x$ as long as $|x-d|<$ $100 \mathrm{msec}$ (regardless of tempo). It would seem that a value of $100 \mathrm{msec}$ is too large to be "tolerated" at most tempi and should be scaled in proportion to the base duration.

Finally, further studies along these lines should perhaps examine the perceptual correlates of some of the findings mentioned above in production paradigms. For instance, does the tendency to produce durations with ratios of 2:1 (Fraisse, 1963; Povel, 1981) also bias our perception of intervals so that they form a simple ratio? Also, the change in discriminability of a duration as a function of its context (i.e., the complete sequence) should be investigated.

\section{REFERENCES}

AвEL, S. M. Discrimination of temporal gaps. Journal of the Acoustical Society of America, 1972, 52, 519-524.
Allan, L. G. The perception of time. Perception \& Psychophysics, $1979,26,340-354$.

Best, P. R., \& Bantlett, N. R. Effect of stimulus interval and foreperiod duration on temporal synchronization. Journal of Experimental Psychology, 1972, 95, 154-158.

Creelman, C. D. Human discrimination of auditory duration. Journal of the Acoustical Society of America, 1962, 34, 582593.

Fraisse, P. [The psychology of time] (J. Leith, trans.). London: Eyre \& Spottiswoode, 1963.

Gabrielsson, A. Performance of rhythm patterns. Scandinavian Journal of Psychology, 1974, 15, 63-72.

GETTY, D. J. Discrimination of short temporal intervals: A comparison of two models. Perception \& Psychophysics, 1975, 18, $1-8$.

GETTY, D. J. Counting processes in human timing. Perception \& Psychophysics, 1976, 20, 191-197.

Longuet-Higains, H. C. Perception of melodies. Nature, 1976, 263, 646-653.

LunNy, H. W. M. Time as heard in music and speech. Nature, 1974, 249, 592.

Michon, J. A. Timing in temporal tracking. Assen, The Netherlands: Van Gorcum, 1967.

Povel, D. J. Temporal structure of performed music. Some preliminary observations. Acta Psychologica, 1977, 41, 309 320.

PoveL, D. J. Internal representation of simple temporal patterns. Journal of Experimental Psychology: Human Perception and Performance, 1981, 7, 3-18.

RAsch, R. A. Synchronization in performed ensemble music. Acustica, 1979, 43, 121-131.

Sтотт, L. H. The discrimination of short tonal durations. Unpublished doctoral dissertation, University of Illinois, 1933.

(Manuscript received September 8, 1981; accepted for publication October 4, 1981.) 